\title{
Stage IIB Colon Cancer AJCC v8
}

National Cancer Institute

\section{Source}

National Cancer Institute. Stage IIB Colon Cancer A/CC v8. NCI Thesaurus. Code C134281.

Stage IIB includes: T4a, N0, M0. T4a: Tumor invades through the visceral peritoneum (including gross perforation of the bowel through tumor and continuous invasion of tumor through areas of inflammation to the surface of the visceral peritoneum). NO: No regional lymph node metastasis. M0: No distant metastasis. (AJCC 8th ed.) 